PÉREZ GONZÁLEZ, S., «El Derecho en la sociedad global del riesgo», REDUR 6, diciembre 2008, pp. 95-107.

ISSN $1695-078 \mathrm{X}$

\title{
EL DERECHO EN LA SOCIEDAD GLOBAL DEL RIESGO
}

\author{
Sergio PÉREZ GONZÁLEZ \\ INVESTIGADOR DEL ÁrEA DE FILOSOFÍA DEL DERECHO \\ UNIVERSIDAD DE LA RIOJA
}

SUMARIO: I. Introducción. II. Concepción sociológica. III. Concepción jurídica. IV. Legitimidad social del sistema jurídico. V. La sociedad global y la concepción jurídica clásica a prueba. VI. Crisis y reformulación de la concepción jurídica clásica. VII. Recapitulación de riesgos. VIII. Bibliografía.

RESUMEN: La globalización y la sociedad del riesgo ponen a prueba la concepción clásica del derecho como sistema social. El marco tradicional -en el que el derecho ordena la sociedad- entra en crisis debido a la extraordinaria complejidad de una realidad en la que los acontecimientos se suceden con cada vez mayor celeridad. Esta situación provoca que el sistema jurídico ya no desarrolle una función aseguradora de nuestras vidas, sino que pase a convertirse en una fuente de riesgos e imprevisiones.

PALABRAS ClAVE: Derecho, sociedad, globalización, riesgo.

TITLE: The Law in the Global Risk Society.

AвSTRACT: Globalization and Risk Society test the classical notion of Law as a social system. The traditional frame -in which Law rules society- enters into crisis due to the extraordinary complexity of a reality in which events happen faster and faster. This situation causes that the legal system does not develop a life insurer function anymore, instead it becomes a source of risks and improvidences.

KEYWORDS: Law, society, globalization, risk.

\section{Introducción}

El derecho es, como saben los juristas, un ámbito relativamente estanco en el que operar conforme a códigos propios. Basta, sin embargo, un vistazo multidisciplinar para constatar que el derecho es, además, un subsistema social articulado para percibir síntomas de la realidad circundante, dispuesto para reformularse. El derecho es, por tanto, una

\footnotetext{
${ }^{\text {I}}$ Este artículo ha sido elaborado gracias, en parte, al programa Colabora de la de la Consejería de Educación, Cultura y Deporte de La Rioja.
} 
integridad trasladable que precisa ser convenientemente auditada dadas las características de un entorno cada vez más acucioso, cada vez menos reducible al viejo marco.

Mediante estas líneas pretendemos analizar -en el plano conceptual- la estructura y función del sistema jurídico a la luz de la nueva realidad social y en contraste continuo con el derecho ya existente.

No pretendemos una aproximación casuística que descienda a la concreción de las distintas disciplinas jurídicas, sino más bien una interpretación holística del derecho en tanto que sistema orgánico integral, actualizado en su estructura para afrontar las nuevas circunstancias. Será mediante esta interpretación como podremos barruntarle un rumbo -o deriva- al derecho, de manera que las líneas que siguen puedan suponer una aportación crítica que sirva, a su vez, para calibrar mejor la complejidad de nuestra realidad.

De esta manera este artículo debe comprenderse en el ámbito delimitado por la ciencia socio-jurídica en un sentido estricto, ya que trata de describir los vínculos entre la sociedad como sistema complejo y su más acotado subsistema jurídico. Más concretamente nos referiremos a la sociedad occidental de las últimas décadas -suficientemente diferenciada de otras- y a la recomposición práctica de la teoría y ciencia jurídicas.

Sobre el plano que delimitan estos ejes trasladaremos el lenguaje propio de los analistas de la llamada posmodernidad para así comprender las consecuencias prácticas que -a grandes rasgos conceptuales- causa la sociedad en el derecho y, a la inversa, la práctica jurídica en la sociedad como ámbito global de actividades.

\section{Concepción sociológica}

Con el propósito indicado nos servimos de la terminología que la sociología viene usando en los últimos tiempos para referirse a la sociedad como sociedad del riesgo, en un modo de imagen ideal. ${ }^{2}$ Esta imagen abarca prácticamente todos los ámbitos de actividad y desarrollo sociales, de manera que puede ser abordada desde muy diferentes puntos de vista: el medioambiente, la economía, la política, el derecho, etc. sin embargo, para todos esos ámbitos, tiene validez un factor común: la globalización.

La concepción de la sociedad del riesgo es la consecuencia teórica de una inminente realidad social caracterizada, básicamente, por el aumento exponencial de la complejidad relacional, articulada y sustanciada en todo el planeta. Es la consecuencia de «la gran transformación que se produce aceleradamente desde mediada la década de I970». ${ }^{3}$

De esta complejidad -cuya reproducción en el tiempo y en el espacio se presupone inevitable- se desprenden, en opinión de los conceptualizadores de la sociedad del riesgo, consecuencias que, en ocasiones, resultan cuanto menos perturbadoras. Esas consecuencias son los riesgos y peligros que, a modo de metonimia, dan título a esta nueva sociedad posmoderna: «A partir de las crisis energéticas, de la inestabilidad monetaria y de la crisis financiera de los años setenta, tanto las amenazas como los riesgos se sucedieron con un

\footnotetext{
${ }^{2}$ Véanse a este respecto las obras fundamentales sobre esta interpretación sociológica: BECK, U., La sociedad del riesgo. Hacia una nueva modernidad, trad: Jorge Navarro, Daniel Jiménez y $\mathrm{M}^{a}$ Rosa Borrás, Barcelona, Paidós, 2006, Luhmann, N., Sociología del riesgo, trad: Silvia Pappe, Brunhilde Erker y Luís Felipe Segura, México, Univ. Iberoamericana, 2006 o GidDEns, A., Consecuencias de la modernidad, trad: Ana Lizón Ramón, Madrid, Alianza, 1994

${ }^{3}$ Capella, J.R., Fruta prohibida. Una aproximación histórico-teorética al estudio del derecho y del estado, Madrid, Trotta, I997, p. 238
} 
ritmo cada vez más intenso»; ${ }^{4}$ buscando unas coordenadas que den concreción al origen del proceso, podemos servirnos de las palabras de Juan Ramón Capella: «A principios de la década de 1970 el Club de Roma [...] llamó la atención del mundo sobre un problema que hasta entonces prácticamente no había sido objeto de debate público: el problema de los límites del crecimiento». ${ }^{5}$

Según estos autores, la complejidad que se alcanza en determinados ámbitos llega a ser tal que amenaza con desbordar la capacidad de control que, en su origen, se creía tener sobre aquéllos. Y esta circunstancia debe ser objeto de reflexión (en un sentido estricto del término) en la medida en que el progreso puede convertirse en un proceso de autodestrucción sin retorno, ya que el resultado de aquellos cambios «fue el declive de la capacidad estatal para dirigir racionalmente el funcionamiento global del sistema económico». ${ }^{6}$

Desde este criterio de valoración del cambio social procedemos a analizar y comprender el fenómeno jurídico. Procedemos, por tanto, no solamente a dar sentido a la producción jurídica desde la realidad social que supone la globalización, sino también, y sobre todo, procedemos a apuntar la función que, a su vez, el derecho desarrolla en la dinámica social de la globalización; y esto lo hacemos en clave, precisamente, de riesgos causados por la complejidad, es decir, analizando los riesgos que se desprenden desde el ámbito jurídico para recaer en la sociedad como sistema global.

En esta línea nos ocuparemos del derecho entendido como sistema social sin analizar las distintas formas concretas que éste puede tomar, sino sobre todo ponderando el modo en que la concepción ya formada del derecho es capaz de asumir esas nuevas manifestaciones al rebufo de los cambios sociales $y$, hasta qué punto, su posible incapacidad de asunción de los mismos genera riesgos en el sentido apuntado a través de la idea de la sociedad del riesgo.

\section{Concepción jurídica}

Conviene a este propósito tomar en consideración la historiografía del derecho en la medida en la que ésta puede ayudar a una comprensión contrastada del tipo de estructura jurídica que se desarrolla paralela a la globalización. Conviene, por tanto, tener presente el itinerario de las distintas concepciones jurídicas que se han sucedido a lo largo del desarrollo capitalista para así situar con mayor criterio al derecho actual en un momento de extremada volatilidad social.

Sirviéndonos de las categorías históricas establecidas con relativa unanimidad, podemos situar el nacimiento jurídico y, por tanto, formal del capitalismo en el final del siglo XVIII.? A este efecto, las primeras producciones jurídicas de enjundia afines al nuevo sistema económico las situamos en las declaraciones de derechos. El elemento cambiante fundamental que trae consigo el capitalismo -en lo que nos interesa a este respecto- es el principio básico informador del sistema: del régimen feudal teocéntrico -sobre el que se sustentaban privilegios de origen natural o divino- se da paso a un régimen antropocéntrico en el que el sujeto, el ser humano, se convierte en principio y referencia originaria para el resto de producción jurídica.

\footnotetext{
${ }^{4}$ FARIA, J.E., El derecho en la economía globalizada, Madrid, Trotta, 200I, pp. 99 y 100

${ }^{5}$ CAPella, J.R., op.cit. p. 235

${ }^{6}$ FARIA, J.E., op.cit. p. IOO

${ }^{7}$ Para el desarrollo esquemático de este itinerario Vid. Blanco GonZÁlez, A. [et al.], Filosofía del derecho. Las concepciones jurídicas a través de la historia, Madrid, UNED, I999
} 
A partir de este giro se suceden a lo largo de los años y territorios de desarrollo capitalista una serie de concepciones jurídicas que forman una cierta dialéctica entre ellas: ese primer iusnaturalismo formalista que surge entre los pensadores de la revolución francesa se desarrolla, sobre todo en Alemania, a través de una concepción comunitaria y moral promovida por los grandes filósofos idealistas, con lo que ello comporta para los fundamentos del Estado y la Nación. El derecho, por tanto, se articula en función de dos concepciones: la codificación, fundada sobre la idea ahistórica que comporta la abstracción del sujeto, y el historicismo que, frente a la razón abstracta, desarrolla una idea histórica, una razón concreta, que emana del pueblo como sujeto colectivo.

En cualquier caso, el giro fundamental en la inspiración jurídica estaba dado. El derecho se desarrolló con arreglo formal a la referencia humana, sea a un sujeto universal y eterno o sea a una comunidad de destino concreta. «La mutación antropológica llevada a cabo en la época moderna y que culmina en la constitución del tipo moderno de hombre y de sociedad capitalista tiene en su misma base el cambio en la visión de las relaciones sociales que trae consigo el giro». ${ }^{8}$ En definitiva, el antropocentrismo y la subjetividad se habían institucionalizado como referencia de una nueva época. ${ }^{9}$

Desde estas bases se desarrolló el positivismo jurídico del siglo XIX (enmarcado en la corriente global de positivismo científico) frente al que se situó, posteriormente, una tendencia antiformalista que obtuvo relativa fuerza a través de la escuela neokantiana, de cuyos preceptos fundamentales se nutrió quien, paradójicamente, sería el artífice de la formulación formalista del derecho por antonomasia: Hans Kelsen.

A través de estos trazos sintéticos hemos pretendido, simplemente, tener presente la dinamicidad de las concepciones jurídicas que, desde una originaria idealización de la labor del derecho en pro de la consecución de valores inherentes al ser humano, concluyen en una gran teoría del derecho -la kelseniana- que, pareja a la diferenciación funcional propia de la globalización, aboga por el desarrollo del derecho como técnica, como sistema autopoiético axiológicamente neutral y, si acaso, conexo a aquellos principios originarios a través de la norma fundamental. Digamos que la teoría kelseniana supo mantener el carácter antropocéntrico del derecho precisamente al asumir las constituciones como cúspide (en su sentido formal, pero sobre todo material): «La sustitución del poder estatal no consensual y autolegitimado por otro basado en el consenso y legitimado por los súbditos desembocó directamente en un acto constituyente». ${ }^{\text {IO }}$

Evidentemente, la teoría de Kelsen ha sufrido variaciones en la medida en que el entorno social así las ha exigido. Si bien la pirámide kelseniana y su cúspide constitucional han sido una referencia obligada para las estructuras jurídicas de muchas democracias, ${ }^{\text {II }}$ no es menos cierto que su cerrazón formal ha sido relativizada en tanto que los cambios sociales exigían adaptaciones jurídicas para las que no servía la rigidez de un estricto

\footnotetext{
${ }^{8}$ Mercado Pacheco, P., «Transformaciones económicas y función de lo político en la fase de la globalización», Anales de la Cátedra Francisco Suárez, n 32, I995, p. I29

9 A este respecto resulta especialmente ilustrativo el capítulo sobre La modernidad y la constitución de la subjetividad abstracta: la mediación entre individualismo $y$ orden social, en BARCELLONA, P., El individualismo propietario, Madrid, Trotta, I996, pp. 42 y ss., así como el capítulo La vita activa y la época moderna, en ARENDT, H., La condición humana, Barcelona, Paidós, I998, pp. 277 y ss.

Io Grimm, D., Constitucionalismo y derechos fundamentales, trad: Raúl Sanz Burgos y José Luís Muñoz de Baena Simón, Madrid, Trotta, 2006, I79

${ }^{\text {II }}$ «En nuestros días, el número de estados que aún se gobiernan sin constitución es insignificante. [...] Es posible considerar su propagación universal como indicio del atractivo ejercido por la idea de que el poder político está necesitado de legitimación jurídico constitucional y de que ha de ser ejercido sobre bases constitucionales si aspira a ser reconocido» GRIMM, D. op.cit. p. I75.
} 
imperio de la ley, ya que «las modernas actividades propias del Estado de bienestar no eran previsibles en los orígenes de la constitución»..

De este modo, en los países de nuestro entorno, las democracias han admitido distintas fuentes de derecho más allá de la mera literalidad de la ley; así -y en ocasiones dando prevalencia a estas otras fuentes- el derecho positivo tiende constantemente a un reciclaje con referencia continua en las demandas de los cambios sociales y económicos, hasta el punto de poder afirmar que la disposición del derecho como técnica en el sentido kelseniano ha deparado una verdadera tecnificación del ámbito jurídico.

\section{Legitimidad social del sistema jurídico}

Muchos autores, estudiosos de Kelsen y de su legado, consideran que esta disposición del derecho como técnica axiológicamente neutral supone un modo de verdadera ejecución homogeneizante de los valores y principios primigenios, reconocidos como inspiradores del resto de producción jurídica en la norma fundamental kelseniana. ${ }^{13}$ En cierto modo - para estos neopositivistas- mediante esta técnica se da sustancia a la retahíla de conceptos abstractos que, originariamente, sólo se resolvían en la mente de los voluntariosos legisladores: igualdad, libertad, solidaridad. Éste ha sido el modo en que, según Bobbio, «se ha realizado (al menos tendencialmente) el gobierno de la ley en lugar del gobierno de los hombres». ${ }^{\text {I4 }}$

Digamos que, considerando la figura ilustrativa clásica, la cúspide de la pirámide que forma el sistema jurídico siempre se mantiene constante, inspirando mediante los resortes colocados al efecto la continua ampliación de la base de la misma pirámide en función de las exigencias sociales y, por tanto, haciendo efectivos los mismos principios y valores de la cúspide para las nuevas condiciones materiales, ya que «el bien común no podía ya hacerse pasar por una consecuencia automática de la libertad individual, sino que había de ser conseguido de forma activa, también en condiciones de libertad», ${ }^{\text {15 }}$ constatando a su vez la función estabilizadora que para la ciudadanía supone la posibilidad de remisión a un texto incuestionable. ${ }^{16}$

Esta interpretación se mantiene relativamente rígida ante los nuevos cambios sociales, ya que no existe alternativa formal al Estado como organización jurídica socialmente estabilizadora, hasta el punto de que las organizaciones supraestatales -como la UE- imitan comportamientos jurídicos propios de los estados como el de aprobar sus propias constituciones legitimadoras. En este sentido, Mercado Pacheco apunta que «en esta tarea de generación de armonía social, el Estado, bajo éste u otro nombre, es difícil que pueda ser sustituido por lejanas instancias supraestatales, por eficaces que estas lleguen a ser en la gestión de lo económico». ${ }^{\text {I7 }}$

\footnotetext{
${ }^{\mathrm{I} 2}$ GRIMM, D. op.cit. p. I76.

${ }^{13}$ Cabe destacar en esta línea la filosofía analítica desarrollada por la Scuola di Torino (Vid. OpochER, E., Lezioni di filosofia del diritto, Padova, Cedam, I993, p. 252 y ss.).

${ }^{14}$ Cit. en BARCellona, P. op.cit. p. 23.

${ }^{15}$ GRIMM, D. op.cit. p. I86.

${ }^{16}$ «La constitución carece actualmente de un equivalente funcional en su tarea de estabilizar, trascendiendo a las generaciones, un consenso fundamental históricamente alcanzado, con su efecto de descarga y control. Por tanto, es en esta función donde sigue encontrándose su soporte más importante; la renuncia a la constitución sería una pérdida en términos de paz social y de cambio controlado» GRIMM, D. op.cit. pp. 201 y 202.

${ }^{17}$ Mercado PaCheCo, P. op.cit. p. I24.
} 
Sin embargo, otras interpretaciones consideran que esta situación de vinculación constante entre la base de la pirámide y su cúspide es un modo de apriorismo ideal, de manera que, en atención a la complejidad social, no necesariamente la producción jurídica pareja a la misma emana -y se transmite mediante inferencias lógicas- de los principios y valores originarios. El proceso lógico, así, no garantiza resultados igualmente lógicos o, en palabras de Capella, «los procedimientos democráticos se han de ver como condiciones necesarias, pero no siempre suficientes, para la legitimidad de las decisiones políticas». ${ }^{18}$

Estas hipótesis se ponen a prueba en tanto que aumenta cuantitativamente aquella complejidad social hasta el punto de ser categorizada como un nuevo estadio cualitativo: la globalización. Un nuevo estadio del desarrollo social que demanda respuestas novedosas del sistema jurídico.

\section{La sociedad global y la concepción jurídica clásica a prueba}

La globalización, entendida como significante de cambios sociales a escala mundial, exige del sistema jurídico una reacción tendente a la adecuación. Una vez puesta en marcha esa adecuación, desde el punto de vista socio-jurídico resulta capital analizar el modo en que la concepción jurídica dominante asume el proceso, ya que de una parte el derecho reinventa su sustancia, su tendencia, su ritmo, mientras que, de otra parte, intenta mantener su función legitimadora clásica propia de las constituciones, sometiendo su nueva morfología y estructura interna a los viejos valores.

La globalización, por tanto, pone a prueba el ideal jurídico y pone en crisis su capacidad funcional en la sociedad actual: «las transformaciones sociales, políticas, económicas y culturales ya apuntadas han venido a exigir una nueva reflexión sobre los problemas centrales de la Teoría General del Derecho, desde el de los modelos jurídicos o el de los métodos hermenéuticos y las fuentes, hasta el de la integración del ordenamiento y las relaciones entre legalidad y legitimidad». ${ }^{19}$

La cantidad e importancia de los cambios sociales suponen, así, un modo de calibrar fehacientemente la función que asume el derecho de inspiración kelseniana en nuestra sociedad. La globalización dispone un escenario complejo que -de modo paradójico- resulta especialmente clarividente. Del modo en que el derecho como sistema cerrado se adecua a la nueva complejidad social se pueden deducir las referencias de sentido del sistema jurídico, poniendo en duda, por tanto, la representación ideal de la pirámide kelseniana y sus igualmente ideales referencias de sentido.

En esta nueva dinámica en la que «la acción social se entrelaza globalmente y las consecuencias de la intervención humana resultan crecientemente distantes y laberínticas», ${ }^{20}$ el derecho debe hacer frente a muchas cuestiones novedosas que se sustancian en otros tantos ámbitos jurídicos: nuevas relaciones internacionales y revisión del derecho internacional, nuevas relaciones laborales y revisión del derecho del trabajo, derecho informático, derecho y bioética, derecho de los animales, derecho medioambiental, etc. $^{2 \mathrm{I}}$

\footnotetext{
${ }^{18}$ CAPELLA, J.R., op.cit. p. 238

${ }^{19}$ FARIA, J.E., op.cit. p. IO6.

${ }^{20}$ CAPELla, J.R., op.cit. p. 240.

${ }^{21}$ Para dar cuenta de la complejidad de determinados casos, Vid. «la cuestión de la patentabilidad de los seres vivos y de los genes humanos» en EstÉVEZ ARAUjo, J.A., «Cesiones de soberanía: la OTAN, la Unión Europea y
} 
La tecnificación del derecho es tal que, volviendo a nuestro propósito original, podemos afirmar que la reproducción del sistema jurídico supone, a determinada escala, la creación de riesgos derivados de los propios progresos incontrolados del derecho como técnica. Se puede sostener que el derecho no escapa a la afirmación de Grimm: «La utilización de nuevas técnicas [...] provoca riesgos que superan muchas veces los peligros de la primera fase de la industrialización». ${ }^{22}$

La tecnología que la nueva sociedad pone a disposición de la función jurídica supone que ésta puede aprehender la realidad social cambiante con una inmediatez y un grado de concreción de casos sin precedentes: «...los nuevos problemas generados por las transformaciones del orden económico internacional, [...] al exigir decisiones ad hoc desde el punto de vista temporal, social y temático, habían conducido a las normas de derecho económico, laboral, de la seguridad social y tributario a ser continuamente reformuladas y reinterpretadas caso a caso.». ${ }^{23}$

La producción legislativa de los parlamentos, así como el resto de elaboración reglamentaria de administraciones y organismos diversos, es capaz de regular los aspectos más nimios de las vidas más corrientes con precisión. El derecho, por tanto, desarrolla su técnica y su complejidad en consonancia a cómo lo hacen el resto de subsistemas sociales, de manera que se conforma una vertiginosa dialéctica de progreso y de continuos cambios en la base de la pirámide, aunque de relativa estabilidad en la cúspide de la misma, arriba, entre las nubes.

Sin embargo esta doble vertiente del derecho actual (estaticidad en la cúspide, dinamicidad en la base) suscita ciertas sospechas de incompatibilidad y disfuncionalidad, hasta el punto de poder titular el proceso actual como «de ingobernabilidad sistémica o crisis de gobernabilidad por los estudiosos de la ciencia política. Los sociólogos y teóricos del derecho la han denominado inflación legislativa, juridificación (o sobrejuridificación) y trilema regulatorio.». ${ }^{24}$

En este sentido, el derecho está en la arriesgada posición de poder reconstruir la realidad atómicamente con arreglo a la necesidad del momento. Este nivel de precisión implica que el desarrollo del derecho necesita, a medida que aumenta su complejidad interna, referencias inmediatas y, por tanto, cada vez más alejadas de los principios de la norma fundamental, de manera que cuando un legislador debe desarrollar con urgencia una regulación concreta debe atender a toda la regulación existente relacionada con el asunto. Dada la complejidad relacional que conlleva la globalización, la regulación existente conectada con cualquier asunto es cada vez menos abarcable, las interconexiones se complican y condicionan, hasta el punto de que la única idea que -más allá de la concreción de los casos- inspira el desarrollo legislativo o reglamentario es la de reformar lo inmediatamente anterior con arreglo a las nuevas necesidades sociales.

Esta toma en consideración de la legislación anterior que inspira al operador jurídico/legislativo está fundamentada, a su vez, en la confianza -probablemente ilusoriaque se deposita en el sistema ideal, por lo que toda decisión concreta que se adecue y conserve la autopoiesis del sistema jurídico estaría avalada -en último (o primer) términopor los principios y valores vinculados con la norma fundamental, de donde, digámoslo así, todo viene y hacia donde todo debe dirigirse.

\footnotetext{
la Organización Mundial del Comercio en la experiencia constitucional española», en J.R. CAPELLA (Ed.) Las sombras del sistema constitucional español, Madrid, Trotta, 2003, pp. I9I y ss.

${ }^{22}$ GRIMM, D. op.cit. p. I9०.

${ }^{23}$ FARIA, J.E., op.cit. p. IOO.

${ }^{24}$ FARIA, J.E., op.cit. p. IOI.
} 
Los técnicos del derecho seguirían, por tanto, al Kelsen más radical, para quien, retomando a Barcellona «el nomos de la tierra es hoy pura regla de juego». ${ }^{25}$

El riesgo en este escenario jurídico es, por tanto, el que se genera con la aplicación de cualquier otro tipo de técnica: la ejecución de la técnica no alcanza -por razones de imperfección mediata- la proyección ideal, de manera que un mínimo desajuste en cualquier momento de la ejecución práctica puede desvirtuar el sentido original del desarrollo legislativo. Como en cualquier otra técnica, el aumento de complejidad en la misma hace aumentar igualmente el riesgo de resultados imprevistos: «cuanto más procura disciplinar y regular todos los espacios, dimensiones y temporalidad del sistema socioeconómico, menos capaz parece de movilizar coherentemente los instrumentos normativos de los que dispone formalmente; cuantas más normas promulga para dirimir conflictos, más multiplica los conflictos». ${ }^{26}$

Inmersos, por tanto, en la complejidad que comporta la globalización, resulta difícil dar por estable la sustanciación concreta del sistema jurídico ideal de inspiración kelseniana; basta una confrontación de los resultados sociales efectivos del nuevo derecho con los valores inspiradores del mismo para constatar esta duda razonable.

\section{Crisis y reformulación de la concepción jurídica clásica}

Proponemos, por tanto, una crisis en la concepción jurídica clásica y su inercia (y esta misma crítica sirve para las variantes institucionalistas del formalismo), de modo que cabe reinterpretar la dinámica del derecho buscándole otras referencias más reales que den sentido a su movimiento.

Como decíamos, la teoría ideal del imperio de la ley y de la autonomía de lo jurídico se fundamenta en una concepción sociológica de diferenciación funcional. En virtud de esta interpretación, el derecho -como sistema social- se reproduciría en base a sus propios elementos de comunicación aunque, evidentemente, sirviéndose de la información que toma de su entorno. Las teorías democráticas que conservan las primeras inspiraciones burguesas, apuntalan esta interpretación con la remisión a los valores fundamentales que siguen configurándose como referencia de todo desarrollo legislativo.

Puesta en crisis esta vinculación por razón -en los últimos tiempos- del aumento de la complejidad social, de las urgencias del derecho y de, por tanto, su propia complejidad interna, quedaría un solo leitmotiv efectivo para el desarrollo del derecho: la adecuación y la adaptabilidad al entorno, de modo que el derecho se desarrolla conforme a sus propios precedentes inmediatos y tratando de adecuar la producción jurídica en vigor a la información obtenida del entorno social. Esta dinámica compone, según Mercado Pacheco, un nuevo tipo de Estado: El Estado comercial abierto, el cual «no implica menos Estado, sino la despolitización de la decisión pública en el gobierno de una economía mundializada y su sustitución por un gobierno técnico-mundial del nuevo orden económico». ${ }^{27}$

Esta tesis se fundamenta en el hecho ya expuesto por el que la tecnificación del derecho podría provocar (o ha provocado ya) la pérdida o, al menos, atenuación de las referencias ideales clásicas, tomándose así como únicas las más inmediatas. De esta inmediatez y, por tanto, del poco margen de maniobra para la elección de una toma de sentido político con fines de Estado, se infiere la ausencia de alternativas en el juego

\footnotetext{
${ }^{25}$ BARCellona, P. op.cit. p. 27.

${ }^{26}$ FARIA, J.E. op.cit. p. IIO.

${ }^{27}$ Mercado Pacheco, P. op.cit. p. I24.
} 
electoral, de manera que, salvo cuestiones especialmente simbólicas, la dinámica jurídica permanece prácticamente inalterada, independientemente del partido en el gobierno. «Los cambios operados por la gran transformación en la esfera del poder vuelven crecientemente infecundos los modos de participación política establecidos por el sistema». ${ }^{28}$

De este modo se produciría lo que podemos llamar una fragmentación del sistema jurídico, formándose diversos subsistemas dentro del propio sistema jurídico en cuanto que la necesidad de referencias inmediatas dispone campos comunicativos inconexos entre sí, a modo de cajas negras que procesan información en su interior, reduciendo su complejidad y mostrando al exterior, por tanto, información procesada y sintética. ${ }^{29}$ Estas cajas negras siguiendo con la imagen ilustrativa- van extendiendo, hacia abajo, la base de la pirámide kelseniana; por esta razón los cimientos de la pirámide se actualizan constantemente, con el riesgo que conllevan las fisuras entre las cajas negras. En otras palabras: la relación integral e ideal que movería el sistema jurídico corre el riesgo de resquebrajarse debido a la extensión y prolijidad a la que conduce la tecnificación, de manera que la producción jurídica sólo puede tomar en cuenta referencias más inmediatas que no garantizan la continuidad de la transmisión de los valores originarios o, como sintetiza Faria: «Su prolífica aunque errática producción legislativa, al aumentar de modo cada vez más desordenado y articulado el número de materias, actividades y comportamientos regulados por textos legales, acaba conduciendo a la ruptura de la organicidad, de la unidad lógica y de la racionalidad sistémica del ordenamiento jurídico. Ello se traduce en la pérdida de la propia capacidad de predeterminación de las decisiones concretas por medio del derecho positivo [...] Esta estructura [...] está caracterizada por la existencia de diferentes microsistemas normativos dotados de una lógica propia y difícilmente adaptables a las pretensiones de coherencia y completitud del ordenamiento». ${ }^{30}$ Incluso, yendo más lejos, se puede dar por cierta la literalidad de las palabras de Mercado Pacheco por las que «el Estado crea, a través de su propia intervención, espacios de sociedad», ${ }^{3 \mathrm{I}}$ en la medida en que su producción jurídica fragmentada reestructura formalmente la realidad social.

De todo lo anterior no puede deducirse que buena parte de la producción jurídica actual -marcada por la necesidad de atención al proceso globalizador- no contenga cierta inspiración humanista y tienda, ocasionalmente, a la consecución de los valores primigenios de las democracias. No cabe duda de que, a pesar de la tecnificación extrema, sigue existiendo un elemento humanista, ético, que sigue marcando en parte la producción legislativa. Sin embargo no es menos evidente que este factor es marginal y decadente frente a la computerización y automatización de respuesta por la que se caracteriza el derecho de la posmodernidad. Sin embargo, antes que resultar contraproducente en el proceso de adaptación al entorno globalizado, este elemento ético referido sirve para mostrar hiperbólicamente una cierta operatividad humanista -a través de algunas leyes llamadas sociales, extraordinariamente popularizadas y fácilmente reconducibles a la abstracción de aquellos valores originarios-. Funcionalmente disponen, por tanto, un modo de promoción de aquellos principios constitucionales casi olvidados entre la prosaica técnica jurídica que colma el sistema, modo mediante el cual la adaptación al entorno socioeconómico -simbolizado en la globalización- pueda resultar menos traumático -dicho esto sin perjuicio de la efectiva materialización de progreso que suponen-. Como dice Faria, «a partir del momento en que se amplía el presupuesto social, cada programa de bienestar consolidado pasa a ser considerado como un derecho inexorablemente adquirido por parte de sus destinatarios. Éste es el motivo por el que su continuidad añade poca legitimidad al

\footnotetext{
${ }^{28}$ CAPELLA, J.R., op.cit. p. 257.

${ }^{29}$ La metáfora más usada para representar la pérdida de organicidad es la del derecho en red, sin embargo la metáfora de los bloques inconexos puede ilustrar más notoriamente la incomunicación entre partes diferenciadas del derecho, respetando el ideal clásico kelseniano y su referencia a la norma fundamental.

${ }^{30}$ FARIA, J.E. op.cit. pp. IO० y II3.

${ }^{31}$ Mercado Pacheco, P. op.cit. p. II4.
} 
Estado, pero su eventual reducción o supresión [...] constituiría una inevitable fuente de pérdida de legitimidad». ${ }^{32}$ Por ello sigue siendo importante para la aceptación integral de la nueva morfología jurídica la remisión ocasional a los derechos sociales, tan directamente emparentados con los valores originarios de la pirámide y cuya ausencia sería -desde el punto de vista negativista que adopta Faria- tan deslegitimadora.

Pero estas leyes de alto poder simbólico no son, evidentemente, el único sostén ideológico del nuevo desarrollo jurídico. La adaptación al entorno, a los cambios económicos, políticos, etc, se sustenta, sobre todo, en una retórica surgida con el proceso globalizador y que, básicamente, reinventa la sustanciación de aquellos viejos valores primigenios que debían inspirar las democracias. Esta reinvención -que pasa por una deconstrucción de la verdad- propone la materialización de aquellos valores a través, precisamente, de la adecuación al entorno socioeconómico simbolizado en la globalización. Dicho con otras palabras: los derechos y valores fundamentales en los que se basa nuestro sistema jurídico sólo podrán ser efectivos y plenos en la medida en que la comunidad a la que pertenecemos (Región, Estado, organización supraestatal, etc...) se adecue con la celeridad y urgencia necesarias al entorno comercial, financiero, tecnológico, etc... sólo así los ciudadanos de ese Estado serán sujetos con plenos derechos. Es, por tanto, el propio sistema jurídico el que, tácitamente, acepta la insuficiencia de los valores primigenios como informadores fundamentales del resto de producción jurídica, exigiendo un modo de equilibrio con el nuevo valor globalización.

La extensión de esta retórica alcanza los fundamentos de incontables resoluciones, ordenes o leyes en las que a menudo la globalización, la creación de riqueza o la innovación se configuran como referencias inspiradoras, ya que «el horizonte intelectual está clausurado por el dogma del crecimiento económico». ${ }^{33} \mathrm{Y}$ si, dado el caso cíclico, es el propio crecimiento económico el que entra en crisis, la maquinaria jurídico política se adecua hasta el punto de hipotecar la materialización de cualquier otro tipo de derecho a la recuperación y puesta a punto del propio crecimiento económico, idea basal sobre la que edificar el resto del derecho.

En cierto modo la urgencia y fragmentación real de la que venimos hablando en el sistema jurídico se legitima -recomponiendo así una nueva pirámide ideal- paragonando las inspiraciones clásicas de la norma fundamental con la nueva gran inspiración: la globalización.

Por esto llamamos a esta retórica reinvención -o deconstrucción de la verdad- ya que este proceso desmonta las realidades anteriores derivadas de aquellos principios del derecho. Y las desmonta de una manera material, reformando toda la legislación que durante los siglos XIX y XX desarrolló un modo de dar contenido a la metafísica de las revoluciones burguesas (en armonía con las necesidades acumulativas del primer capitalismo). En palabras de Mercado Pacheco, el Estado comercial abierto se encuentra «legitimado exclusivamente en el plano de los hechos por la constitución en valores universales de la racionalidad económica y los imperativos de la eficiencia». ${ }^{34}$

Se recupera en esencia, por tanto, el liberalismo más clásico, aunque -al hacerlo a base de superproducción jurídica- las formas no se parecen. «El estado abierto no deja de intervenir en la economía, aunque su modo de operar [...] se contrapone al propio del estado intervencionista», ${ }^{35}$ hasta el punto de que «la apertura del Estado a la economía globalizada

\footnotetext{
${ }^{32}$ FARIA, J.E. op.cit. p. IO3.

${ }^{33}$ CAPELla, J.R., op.cit. p. 236.

${ }^{34}$ Mercado Pacheco, P. op.cit. p. I24.

${ }^{35}$ CAPELLA, J.R., op.cit. p. 232.
} 
exige una decidida y copiosa intervención del Estado». ${ }^{36}$ Incluso, tal y como apunta Cassese, no sólo aumenta la intervención de cada Estado, sino que aumenta también, paralelo a la globalización, el número de Estados y, por tanto, el número de instituciones y órganos políticos para un mismo territorio. ${ }^{37}$

De hecho basta sustituir el viejo laissez faire, laissez passer para, con disimulo, proclamar el nuevo faites faire, faites passer y así enmascarar un mismo propósito. El Estado hace para que se pueda hacer y pasar, el derecho se ha convertido en un modo de procedimentar la economía, el crecimiento, la globalización: «Todo ello tiende a conducir al derecho positivado por el Estado a disciplinar no tanto los comportamientos cuanto los procedimientos». ${ }^{38}$

Pero la legitimación de este nuevo Estado comercial abierto no sólo pasa por «el plano de los hechos», como dice Mercado Pacheco, sino que el proceso referido también desmonta (o mejor, complementa) el ideal anterior, hasta el punto de que la dinámica jurídica ya no puede sostenerse exclusivamente en la nomenclatura de aquellos valores primigenios, sino que debe completarse mediante la nueva nomenclatura, de manera que el lema de las normas fundamentales posmodernas mantiene su tributo a los clásicos aunque insertado en la nueva y rutilante moldura: libertad, igualdad y globalización, como si la globalización fuera un principio inspirador que añadir a los anteriores y no la simbolización del entorno social, cuyos efectos debería filtrar el sistema jurídico para dotar de cierta seguridad a la población.

Este modo ideológico hoy preponderante propone, por tanto, una circunvalación retórica que proyecte un orden jurídico estable a la sociedad; una circunvalación retórica que pretende que, lo que desde el punto de vista analítico describimos como una realidad de adecuación urgente del derecho a las demandas del crecimiento económico, sea entendido como un proceso de orden global, en el que el derecho se desarrolla armónicamente en función de la nueva verdad inspiradora: la globalización.

Se puede afirmar que, amparado en esta nueva verdad, el derecho desarrolla un contenido libre aunque formalmente lógico y, por tanto, democrático y legítimo.

De este modo, por un lado el derecho desarrolla argumentaciones imprecisas y a menudo contradictorias entre sí o, en palabras de Faria, «la tendencia es que cuanto mayor sea la complejidad socioeconómica, más se acentúe el carácter polisémico de las normas, a causa de estos conceptos flexibles, porosos, tópicos, indeterminados y programáticos»;39 Mientras, por otro lado, esas imprecisiones y contradicciones no deslegitiman su operatividad, ya que «la función de la polisemia es ayudar a la ley a permanecer estable al mismo tiempo que permite su adaptación, por medio de la interpretación judicial, a las nuevas circunstancias y singularidades de una sociedad compleja». ${ }^{40}$

Se puede afirmar, en esta lógica, que la nueva pirámide jurídica de la que hablábamos se ha reinventado con arreglo a un nuevo principio inspirador que unir a los

\footnotetext{
${ }^{36}$ Mercado Pacheco, P. op.cit. p. I22.

37 «el fenómeno de la globalización no es ni tan siquiera coherente, porque, mientras debería verse acompañado de una reducción del fenómeno estatal, se mueve de forma paralela a su aumento, al menos cuantitativo. En Europa existían, después de la Primera Guerra Mundial, 23 Estados; hoy son 50. La proliferación estatal es creciente: desde I9०o hasta la mitad del siglo ha surgido más de un Estado al año; desde entonces hasta I990, más de dos; en los años noventa, más de tres al año.» CASSESE, S., La globalización jurídica, trad: Luís Ortega, Isaac Martín Delgado, Isabel Gallego Córcoles, Madrid-Barcelona, Marcial Pons, 2006, p. I5.

${ }^{38}$ FARIA, J.E. op.cit. p. I2I.

${ }^{39}$ FARIA, J.E. op.cit. p. II2.

${ }^{40}$ FARIA, J.E. op.cit. p. II3.
} 
clásicos: la complejidad del entorno social que circunda la pirámide y la incapacidad de ésta por aprehenderla al completo ha provocado que el propio sistema jurídico haya reducido aquella complejidad circundante a una palabra (globalización) y la haya colocado -como en un juego de estrategia con fichas- en la cúspide, como un principio constituyente más. «Por eso cabe calificar este discurso, legitimador del soberano difuso, de iusnaturalista», ${ }^{4 \mathrm{I}}$ es decir, el modo de actualizar aquel iusnaturalismo formalista nacido de las revoluciones burguesas; «Un neoiusnaturalismo de la razón económica. [...] Esta es la mitología de la globalización. Y ningún paso en el terreno de la política, del derecho, de las instituciones y de la democracia puede darse sin poner en cuestión los idola sobre los que se estructura esta concepción del mundo». ${ }^{42}$

\section{Recapitulación de riesgos}

Tras advertir los cambios en las formas, los argumentos, las tendencias y los ritmos que el derecho de la posmodernidad va asumiendo en consonancia con las demandas de la globalización, hemos propuesto una síntesis conceptual final fundamentada en la imagen ilustrativa de la pirámide kelseniana, en la medida en que esta figura puede seguir representando el sistema de legitimación formal del que se sirven los Estados para producir derecho, a la vez que la misma pirámide ha sido capaz de asimilar a su estructura procedimental clásica los cambios sociales simbolizados por la palabra globalización.

Hemos descrito, por tanto, la renovación que viene produciéndose del viejo iusnaturalismo formalista, de modo que el derecho posmoderno ha actualizado los principios inspiradores de la cúspide de la pirámide, transformando el entorno socioeconómico informador pero formalmente ajeno al sistema jurídico- en valor fundamental del nuevo derecho y, por tanto, en elemento formal fundamental del nuevo modo de hacer derecho.

En este sentido, el derecho de la posmodernidad conserva sus formalidades democráticas a través de la norma fundamental y asume condicionantes extraños -relativos a la nueva economía- tomándolos como nuevos principios naturales.

La consecución de esta nueva pirámide ideal conlleva -como hemos visto en el análisis de su composición desde las crisis de los setenta- una serie de riesgos, evidenciados al desmenuzar el proceso en sus elementos técnicos, más allá de la figura ideal.

Insertos en la nomenclatura actual de la sociedad del riesgo, el derecho, como técnica desarrollada al rebufo de la globalización, supone un ejemplo especialmente clarividente de fenómeno generador de riesgos; más aún cuando su nuevo principio inspirador -la necesidad expansionista y globalizadora- induce a una superación eterna de la propia técnica en aras del crecimiento sin límites ni fines comunes concretos.

Estos riesgos que se le desprenden al derecho como sistema social han sido, por tanto, apuntados a lo largo del análisis:

- Riesgo de desintegración, dispersión, pérdida de la organicidad jurídica:«En términos de una situación límite, por lo tanto, este proceso inflacionario terminaría conduciendo a la anulación de todo el sistema jurídico, empezando por su unidad dogmática». ${ }^{43}$ Es decir, no existen ni fines ni principios; existen urgencias que provocan una

\footnotetext{
${ }^{41}$ CAPELla, J.R., op.cit. p. 267.

${ }^{42}$ Mercado Pacheco, P. op.cit. pp. I27 y i28.

${ }^{43}$ FARIA, J.E. op.cit. p. II3.
} 
composición desorientada e incoherente del edificio jurídico, carente de coordinación y dúctil ante presiones puntuales sin sentido definido más allá que el que marca el interés coyuntural.

- Riesgo de contrariedades y arbitrios no fundamentados: «Por este motivo, un ordenamiento jurídico minado por la inflación, por la variabilidad y por la volatilidad de sus dispositivos normativos acaba exigiendo un trabajo interpretativo continuo [...y] la interpretación ya no se concibe como el descubrimiento de la voluntad de la ley, sino como un proceso hermenéutico de comunicación y crítica ideológica a reglas dictadas en el pasado, constituyendo así un acto nuevo, lo que posibilita en el presente una especie de reconstrucción de la realidad. Se pueden así comprender los orígenes de la judicialización de la política». ${ }^{44}$ «La organización social [...] se ocupa de una complejidad tan grande que no puede ser racionalmente anticipada en su totalidad y, por tanto, sólo es posible determinarla legalmente de manera incompleta. [...] Esto hace que el contenido y resultado del acto administrativo no sean ya designados en la ley de forma general y abstracta, sino que se determinen independientemente por la Administración». ${ }^{45}$ Es decir, un modo de subcontratación del contrato social. Un modo de delegación de facultades políticas en individuos no competentes. En cierta manera puede afirmarse que el último mito inspirador del derecho legitima al administrador para reescribir constantemente la subnorma aplicable al caso.

- Riesgo de pérdida de derechos adquiridos: «En el universo del derecho positivo la inflación mina los marcos normativos esenciales de la vida social, impide la seguridad jurídica y acaba por contribuir a la reducción a polvo de derechos legítimamente conquistados». ${ }^{46}$ Es decir, cualquier norma que en otro momento pudiera haberse recogido bajo el estandarte de avance social, se reconceptualiza bajo el decadente rótulo de norma no adaptada al último gran mito, de modo que pase a ser susceptible de revisión o supresión.

- Riesgo de dilución de la efectiva participación política: «El estado abierto regido por un sistema democrático-representativo se basa, obviamente, en la soberanía popular. Al estar limitada esta soberanía, quien tiene limitada objetivamente su capacidad de decisión es la población misma». ${ }^{47}$ Es decir, el déficit democrático propio de cualquier proceso electoral se extiende a lo largo de toda la legislatura en la medida en que apenas puede distinguirse ya un momento de legitimación popular de una u otra alternativa política que marque la producción jurídica por venir, ya que la producción jurídica queda, cada vez más, determinada por la urgencia constante de la coyuntura, eterna coyuntura.

Pero, sobre todo, subsiste el riesgo que pervierte la capacidad reflexiva y de maniobra del Estado para con otros riesgos: el riesgo por el cual el derecho deja de ser un procedimiento de control y organización del resto de riesgos producidos en otros ámbitos sociales. El riesgo de que el derecho se convierta tan sólo en un modo de conceder visado a la imprevisión, un modo recurrente de medidas provisorias y garantías pospuestas. El riesgo, en definitiva, de que el derecho no sirva para marcarle el rumbo a la globalización, sino para facilitar la deriva social en una complejidad creciente y aparentemente irresoluble.

\footnotetext{
${ }^{44}$ FARIA, J.E. op.cit. p. II2.

${ }^{45}$ GRIMM, D. op.cit. p. 207.

${ }^{46}$ FARIA, J.E. op.cit. p. III.

${ }^{47}$ CAPELLA, J.R., op.cit. p. 264.
} 


\section{Bibliografía}

ARENDT, H., La condición humana, trad: Ramón Gil Novales, Barcelona, Paidós, I998.

BARCELlonA, P., El individualismo propietario, Madrid, Trotta, I996.

BECK, U., La sociedad del riesgo. Hacia una nueva modernidad, trad: Jorge Navarro, Daniel Jiménez y Mª Rosa Borrás, Barcelona, Paidós, 2006.

Blanco GonZÁlez, A. [et al.], Filosofía del derecho. Las concepciones jurídicas a través de la historia, Madrid, UNED, I999.

CAPELLA, J.R., Fruta prohibida. Una aproximación histórico-teorética al estudio del derecho y del estado, Madrid, Trotta, I997.

CASSESE, S., La globalización jurídica, trad: Luís Ortega, Isaac Martín Delgado, Isabel Gallego Córcoles, Madrid-Barcelona, Marcial Pons, 2006.

ESTÉvez ARAUjO, J.A., «Cesiones de soberanía: la OTAN, la Unión Europea y la Organización Mundial del Comercio en la experiencia constitucional española», en J.R. Capella (Ed.) Las sombras del sistema constitucional español, Madrid, Trotta, 2003.

FARIA, J.E., El derecho en la economía globalizada, Madrid, Trotta, 200I.

Giddens, A., Consecuencias de la modernidad, trad: Ana Lizón Ramón, Madrid, Alianza, I994.

GrimM, D., Constitucionalismo y derechos fundamentales, trad: Raúl Sanz Burgos y José Luís Muñoz de Baena Simón, Madrid, Trotta, 2006.

Luhmann, N., Sociología del riesgo, trad: Silvia Pappe, Brunhilde Erker y Luís Felipe Segura, México, Univ. Iberoamericana, 2006.

MerCAdo PaCHeCo, P., «Transformaciones económicas y función de lo político en la fase de la globalización», Anales de la Cátedra Francisco Suárez, n 32, I995, p. I29.

OpOCHER, E., Lezioni di filosofia del diritto, Padova, Cedam, I993. 